\title{
Young Children's Recitation and Comprehension of Information Presented by Songs
}

\author{
SANDRA L. CALVERT AND RebeCCA L. BILlingsLey \\ Georgetown University
}

\begin{abstract}
In two experiments, young children's recitation and comprehension of content presented in songs was examined. In the first experiment, repeated exposure to a televised song improved young children's verbatim word-for-word memory of incomprehensible French, but not comprehensible English, lyrics. Memory for verbal factual material never improved after exposure to that song, even after repeated exposure to the English version. In the second experiment, children who were exposed to a prose presentation of their phone number remembered this information more often than did those, who heard an original song about their phone number. There was no relation between reciting and understanding that material. Results were interpreted within a modified levels of processing framework, which focuses on superficial versus deeper processing of information.
\end{abstract}

Songs, a part of our oral tradition, were once used to carry messages before written language was widely available. As bards traveled from village to village, they sang tales of conquest and of woe in a musical form that facilitated the memory and transmission of important cultural information (Calvert \& Tart, 1993).

Our musical heritage continues to be a potential vehicle for rememhering information. We all know that certain lyrics can be easily recalled and can provide rather durable memories for years to come, yet we know relatively little about how well children actually process the messages embedded in a song. This study examines whether children think about the meaning of the words that they so easily sing, or do they mindlessly produce those lyrics?

Direct all correspondence to: Sandra L. Calvert, Department of Psychology, Georgetown University, 37th \& O Streets, N.W., Washington, D.C. 20057. 


\section{Children's Processing of Songs and Nursery Rhymes}

Songs, like nursery rhymes, are considered to be memorable to young children. Presumably the phonic properties of rhymes and songs provide an additional structure that children can use to represent information (Sloboda, 1985). This assumption may only be partly true. Although preschoolers' verbatim memory does improve in rhyme over verse conditions (Johnson \& Hayes, 1987), memory of factual content is actually better in verse than in rhyming conditions (Hayes, Chemelski, \& Palmer, 1982).

Hayes and his colleagues (Hayes et al., 1982; Johnson \& Hayes, 1987) used two models to explain these nursery rhyme findings: a levels of processing model (Craik \& Lockhart, 1972), and a transfer appropriate model (Morris, Bransford, \& Franks, 1977). In Craik and Lockhart's (1972) levels of processing model, information may initially be processed at a superficial phonic level (sound) with little regard to the semantic meaning of the content. Hence, rhymes can distract the learner from thinking about the embedded message (Hayes et al., 1982). If children are processing material at a superficial level, then repetition should not improve their comprehension of the material (Craik \& Lockhart, 1972). Rather, children must link information with existing material in memory and elaborate on that material for it to be better understood.

The transfer appropriate model, a refinement of the levels of processing approach, emphasizes that meaningfulness is embedded within the context of particular learning goals (Morris et al., 1977). For instance, adults' retention of rhyming material was superior when they had been exposed to rhyming rather than to semantic acquisition tasks, but their retention of prose material was superior after exposure to a semantic acquisition task (Morris et al., 1977). Thus, children and adults may perceive rhymes as passages that should be memorized verbatim and devote their information processing activities to those that will improve verbatim recitation of the content. By contrast, a prose passage may activate and maximize children's efforts to comprehend material.

Similar effects as those reported in the nursery rhyme literature may well be found in the area of songs. The encoding of songs can be conceptualized as an information processing activity that is sensitive to the temporal and acoustic properties of lyrical content (Sloboda, 1985). On the one hand, the phonic properties of songs may distract children from deeply processing the lyrical message, a prediction in keeping with a levels of processing approach. It is in this approach that children may mindlessly sing the lyrics of a song with little thought to the semantic meaning.

A transfer appropriate model also suggests that songs may lend themselves to verbatim memory, but for a different reason. In this model, children learn a song to sing it. They may not understand factual content because that was never their goal, and their subsequent behavior rarely requires them, or any of us, to understand the lyrics of a song.

Consistent with the nursery rhyme literature (Johnson \& Hayes, 1987), verbatim memory is associated with songs (Calvert \& Tart, 1993; Hyman \& Rubin, 1990; Rubin, 1977). Moreover, comprehension of song lyrics is relatively poor for fourth graders, though it does improve as children move into junior high and high school (Greenfield, Bruzzone, Koyamatsu, Satuloff, Nixon, Brodie, \& Kingsdale, 1987). No one, as yet, has examined very young children's comprehension of song lyrics. That question is of primary importance here. In Experiment 1, we used the levels of processing approach to test the hypothesis that children will be able to sing songs without understanding their meaning. In 
Experiment 2, we used the transfer appropriate model to test the hypotheses that children will be better able to recite content word-for-word when it is presented as a song, but they will be better able to understand that content when it is presented in prose.

\section{Comprehensibility of Content}

If children are processing sung material at a relatively superficial level, then the comprehensibility of the content should have little impact on their comprehension of that content. That is, both comprehensible and incomprehensible song lyrics should be processed shallowly.

This prediction differs from the comprehensibility hypothesis (Anderson \& Lorch, 1983), which predicts that children attend to content when they think they can understand it. For example, as early as preschool, children are preferentially responsive to a televised vignette spoken in their native language over a foreign language (Anderson, Lorch, Field, \& Sanders, 1981). Such findings suggest that young children are in search of meaning (Anderson \& Lorch, 1983).

If children are responsive to comprehensibility, then they should also focus on the meaning of songs rather than how they sound. Meaningful content can be presented aurally or visually (Anderson et al., 1981; Calvert, in press; Greenfield, 1993). If, however, children process songs at a superficial level, then comprehensibility should not improve children's understanding of the verbal or the visual content.

In Experiment 1, we compared these models by exposing children to two televised versions of "Frere Jacques." One version was presented with incomprehensible French lyrics, and the other version was presented with comprehensible English lyrics. We kept the comprehensibility of the visual track constant by showing the same televised vignette. Based on the levels of processing approach, we hypothesized that children would understand the comprehensible English lyrics no better than the incomprehensible French lyrics. Comprehension was assessed by verbal multiple-choice questions and by visual sequencing measures.

\section{Repetition and Rehearsal}

Repetition can improve children's and adults' recitation of sung material (Calvert \& Tart, 1993). However, repetition can also lead to shallow processing if that information is not integrated with existing material (Craik \& Lockhart, 1972).

In Experiment 1, we varied the number of times that children were exposed to a song. Because children were randomly assigned to conditions, we could control for prior exposure to that song. We also asked some children to sing the song with us, the active rehearsal condition, or we simply watched the program with them, the passive rehearsal condition. We hypothesized that the children in the repetition condition, particularly the active rehearsal version, would produce the lyrics better, even though the information should remain at a relatively superficial level. However, we hypothesized that repeated exposurc to the song would not improve children's comprehension of the visual or verbal material because content was being repeatedly experienced at a superficial, not a deep, level. 


\section{The Present Studies}

The purpose of the two experiments presented here was to examine the impact of songs on children's comprehension of verbally-presented content. Based on the findings reported in the nursery rhyme literature (Hayes et al., 1982; Johnson \& Hayes, 1987), the first experiment examined the possibility that songs may be processed at a relatively superficial level at the expense of the semantic meaning. In the second experiment, a transfer appropriate model of information processing, in which task demands are considered in relation to encoding properties, was considered as a way to refine our understanding of the impact of songs on children's comprehension. To do so, song and prose presentations were compared in the second study.

\section{EXPERIMENT 1}

The main purpose of Experiment 1 was to examine the hypothesis that superficial processing of song lyrics can occur with little understanding of the song meaning. Preschool-aged children, who have little accumulated exposure to songs, were selected as participants.

The specific hypotheses were:

H1: Repeated exposures to televised songs will produce higher verbatim memory than single exposures.

H2: Childrenare expected toprocesscontent at a superficiallevel; language comprehensibility will have no impact on verbatim memory or on comprehension.

H3: The rehearsal task involves singing the words verbatim; active rehearsal, in which children sing the lyrics, will improve verbatim memory more than passive rehearsal, in which children simply listen to the lyrics.

H4: Children are expected to process the song at a superficial level; repeated exposures to the visual depiction will not improve children's memory of the pictorial sequence of events, a measure of visual comprehension.

H5: Children are expected to process the song at a superficial level; repeated exposures to the song will not improve memory of multiple-choice items, a measure of visual and verbal comprehension.

\section{Method}

Participants. Participants were forty-eight preschoolers ( $M=49$ mos.), equally distributed by gender. Children, who attended preschool or day care programs in a large metropolitan area, were predominantly Caucasian or African American. Within gender groups, children were randomly assigned to treatment conditions.

Television Treatment Conditions. "Frere Jacques" is a child's song. It's a wake-up song. Specifically, Brother John, a friar, is awakened by church bells ringing.

We created a 20-second televised presentation of "Frere Jacques" by having pictures drawn and animated to represent the story. The visual scenes depicted a friar sleeping in bed, bells ringing, the friar with his eyes open, and finally the friar stretching his arms. 
The song, which was sung by a choir, was then dubbed onto the video track. Two versions, one in English (comprehensible) and one in French (not comprehensible), were created to vary the comprehensibility of the vignette. The choir sang "Frere Jacques" twice for each vignette.

The French script is presented below:

"Frere Jacques. Frere Jacques.

Dormez vous? Dormez vous?

Sonne les matines. Sonne les matines.

Ding dang dong. Ding dang dong."

The English script is presented next:

"Are you sleeping? Are you sleeping?

Brother John. Brother John.

Morning bells are ringing. Morning bells are ringing.

Ding dong ding. Ding dong ding."

\section{Procedure}

Small groups of preschoolers viewed one televised version of the song "Frere Jacques" under varying conditions of language comprehensibility (English vs. French), rehearsal (passive vs. active), and repetition (absent vs. present). The visual track always depicted the sleeping friar who was awakened by ringing bells. The auditory track varied the comprehensibility of the vignette by presenting the song in either English or French. The song was played two times during each exposure. In active rehearsal conditions, children were asked to sing during the second presentation. In passive rehearsal conditions, children were asked to listen to the song one more time. The repetition condition involved repeated exposure to the same vignette for four successive days. The no repetition condition involved exposure for one day only.

Immediately after treatment conditions were completed, each child was individually tested on three memory measures: (1) verbatim recall of song lyrics (recitation); (2) sequencing of visual program events; and (3) recognition of central story events. The latter two measures were used to index comprehension of the program material, as measured by visual integration of program events or by comprehension of the song meaning, respectively.

Verbatim Recitation. First, each child was asked if he or she remembered the song that they had heard on television that week. The Experimenter said, "Let's hear it." She then recorded responses on audio tape and on an answer sheet.

Tapes were later transcribed and scored word-for-word to assess verbatim recitation of the song lyrics. Following procedures developed by Rubin (1977), one point was awarded for each word that was in the correct order. French words were scored as correct when they were pronounced correctly. Any combination of "dings," "dangs," and "dongs" was allowed. This procedure resulted in a total possible score of 30 or 24 for the French and English scripts, respectively. Because there were different numbers of words in the two versions, scores were transformed into percentages. 
Picture Sequencing. Then each child was asked to sequence four still pictures of the vignette just as they had happened in the story. These photographs were the same ones that had been used to create the animated segment.

The picture sequencing measure was administered and scored following procedures developed by Wright et al. (1984). Initially, the experimenter put the four pictures in random order before the child. She then said, "These are some pictures that you just saw on television. I want you to put them in order from the first thing that happened in the story to the last- in a line right in front of you." After the child sequenced the pictures, the experimenter said, "Now tell me what happened in the story."

One point was awarded for each picture that was placed in its correct absolute position. In addition, one point was awarded for each pair of pictures that were correctly placed adjacent to one another. These two scores were summed, resulting in a maximum possible score of 9 .

Multiple-Choice Recognition. Finally, each child answered 4 verbal, multiplechoice items assessing recognition of the central story content. Recognition items were constructed following procedures developed by Collins (1970). First, central items were placed in an open-ended questionnaire. Then 9 adult judges rated each question as central or incidental to the story. Items were retained that had a centrality rating of at least $78 \%$.

All questions and response options were verbal in form. The answers to two questions were presented on the visual track, one answer was presented on the audio and visual track, and one answer was an inference. An example of a multiple-choice item is "How does Brother John wake up?

(a) He hears bells ringing;

(b) He hears birds singing; or

(c) The sun shines in his eyes and wakes him."

The experimenter read each of the four questions aloud, the child selected a response option, and the experimenter circled the responses on an answer sheet.

\section{Results}

The percent of verbatim recitation scores, the number of visual events sequenced correctly, and the number of central events correctly recognized were submitted, in turn, to a 2 (repetition) by 2 (language comprehensibility) by 2 (rehearsal) analysis of covariance with age in months as a covariate. Duncan's follow-up contrasts were used to determine significant differences between means, given a significant $F$ ratio. Significant differences between means are indicated by a different letter superscript.

Verbatim Recitation Scores. The 3 factor ANCOVA computed on verbatim recitation scores yielded a main effect of repetition, $F(1,39)=7.23, p<.01$; qualified by a comprehensibility by repetition interaction, $F(1,39)=4.59, p<.05$. Children's recitation scores were similar after one exposure to the French $(M=16.25 \%$, $S D=30.09)$ or English $\left(M=23.33 \%^{\mathrm{b}}, S D=34.25\right)$ version of the song. However, repetition increased children's recitation of the French $\left(M=61.25 \%^{\mathrm{a}}, S D=28.93\right)$, but not the English $\left(M=28.42 \%^{\mathrm{b}}, S D\right.$ $=32.39$ ) version. There were no effects of age for verbatim recitation of information. 
Picture-Sequencing and Multiple-Choice Recognition Scores. The 3 factor ANCOVA computed on picture-sequencing and multiple-choice recognition scores only yielded age effects. The older children were, the better they understood the sequence of visual story events, $F(1,39)=11.49, p<.01$, and recognized the meaning of song lyrics, $F(1,39)=8.03, p<.01$.

\section{Summary}

In summary, verbatim recitation of the song was improved only in repetition conditions. Successful performance on multiple-choice and picture sequencing tasks was only enhanced by age, not by repeated exposure to a segment.

If verbatim memory simply indexes rote memorization, then the evidence supports the conclusion that songs facilitate shallow processing of verbal content. Children actually memorized the incomprehensible French version of the song better than the English version. As predicted, children didn't understand the comprehensible English version any better than the incomprehensible French version. These findings support the levels of processing model and cast doubt on the overriding importance of program comprehensibility as the reason for children's attention to, and comprehension of, content. However, in the levels of processing model, children should also have memorized the English version of Frere Jacques well. They did not.

Experiment 1 had several potential problems that limited our conclusions. For example, Experiment 1 only examined one song, and that song could have been familiar to some children. The song was also visually depicted which resulted in three ways that children could potentially process the content: the visual, the sung, and the verbal, semantic. Moreover, the song was not contrasted with a prose condition. Perhaps children did not comprehend the information well because they did not interpret the task demands accurately, an interpretation more in line with a transfer appropriate model. The latter limitation made us consider the transfer appropriate model, a refinement of the levels of processing approach, as a way to test and refine our findings.

Experiment 2 tested the transfer appropriate model of information processing by asking children to learn and remember their phone numbers in song and prose conditions. The song was a novel tune, ruling out any potential confound due to prior familiarity. The visual television track was deleted from the experiment to reduce the number of competing tracks that children could potentially process.

\section{EXPERIMENT 2}

The purpose of Experiment 2 was to compare children's memory and comprehension of information presented in song versus prose. According to a transfer model of information processing, if children perceive songs as passages to be memorized verbatim, as adults seem to perceive rhymes (Morris et al., 1977), song presentations of information should be expected to increase recitation of that information. Prose presentations, by contrast, should be perceived as passages to be understood. We examined the transfer appropriate model by teaching children their phone numbers, a task that requires an exact verbatim memory of the numbers.

Our specific hypotheses were that: 
H1: Children who heard a sung presentation would be able to remember a passage about their specific phone number better than children who heard a prose presentation.

H2: Children who heard a prose presentation would be able to understand the use of their phone number better than children who sang about it.

To test these hypotheses, we varied singing and prose presentations about each child's phone number, and, as before, we tested children to see if they could sing and understand the passage. Because repetition was necessary for effective recitation in Experiment 1, all children, except those in the control condition, were repeatedly exposed to their phone number in a singing, a prose, or a combined singing and prose presentation.

\section{Method}

Participants. Participants were 39 four-year-old children $(M=56$ mos.) who attended preschool or day care programs in a large metropolitan area. The ethnic background of children was as follows: 25 were Caucasian, 6 were African American or African, 4 were Hispanic, and 4 were Asian. Within gender groups, the 19 boys and 20 girls were randomly assigned to one of five conditions.

\section{Treatment Conditions and Procedure}

Treatment conditions involved the use of a song versus a prose presentation as a way to: (1) Teach children their specific phone numbers; and (2) Understand the functional importance of that number. The song, an original tune in C-major, was as follows: "My number is \#\#\#-\#\#-\#\#\#\#. If I'm out and about and I find myself alone, I'll tell an adult to phone my home." One condition was a song only; one condition was prose only; and two conditions involved a mixture of a song and prose presentation (i.e., song number/prose passage vs. prose number/song passage). A control condition, which received no treatment, was included to ensure that children did not learn their numbers elsewhere while the study was taking place. A televised depiction was not used because: (a) each child's phone number was unique; and (b) eliminating the visual track reduced the demands on the child's information processing activities.

In the four treatment conditions, each child participated individually in 6 sessions in which he or she interacted with an adult who presented the child's phone number within their respective treatment condition. All children were shown their phone number on a magnetic board using plastic numbers. The child was then encouraged to repeat the targeted material four times with the adult. After repeating the material, the magnetic board was turned away from the child. The Experimenter then asked the child: "What's your phone number?" (recitation); and "What should you do if you are lost?" (comprehension). This same procedure was repeated for each of the six sessions. Children in the control condition were simply asked these questions for each of the six sessions.

\section{Results}

The total percent of times that children recited their phone number correctly and the total percent of times children comprehended the functional importance of their phone 
Table 1. Mean Percent Scores for Recitation of Phone Number by Condition

\begin{tabular}{lc}
\hline Condition & Recitation of Phone Number \\
\hline Control & $2.12 \%^{\mathrm{a}}(\mathrm{n}=8)$ \\
Song Only & $31.12 \%^{\mathrm{a}}(\mathrm{n}=8)$ \\
Prose Only & $66.57 \%^{\mathrm{b}}(\mathrm{n}=7)$ \\
Prose Number/Song Phrase & $31.12 \%^{\mathrm{a}}(\mathrm{n}=8)$ \\
Song Number/Prose Phrase & $33.38 \%^{\mathrm{a}}(\mathrm{n}=8)$ \\
\hline
\end{tabular}

Note: Means with different letter superscripts are significantly different at $p<.05$.

number across all sessions was submitted, in turn, to a 5 (condition) by 2 (gender) betweensubjects analysis of variance. The 2 factor ANOVA computed on children's recall of their phone number yielded a main effect of treatment condition, $F(4,29)=4.29, p<.01$. As seen in Table 1, children in the prose only condition recalled their phone number significantly more often than did those in any other condition. Although their level of performance was higher, the other treatment conditions did not differ significantly from the control group. The 2 factor ANOVA computed on comprehension scores yielded no significant effects. Contrary to prediction, children in prose conditions did not understand what to do if they were lost any better than children who sang those words or who had no treatment at all.

To clarify the relation between recitation and comprehension, a Chi-Square analysis was run. Specifically, all children were scored on their ability to recite their phone number and to understand their phone number's use. Data from the last session were examined. There was no link between comprehension and recitation scores.

\section{GENERAL DISCUSSION}

The purpose of these studies was to examine the impact of songs on children's recitation of, and comprehension of, verbal material. The results suggest that songs are poorly understood by children, an interpretation in keeping with the levels of processing approach (Craik \& Lockhart, 1972).

In Experiment 1, children who were repeatedly exposed to the song "Frere Jacques" did not understand its meaning, even when the lyrics were presented in English. Moreover, repetition increased children's recitation of the incomprehensible French, but not the comprehensible English, lyrics. Only age predicted children's ability to recognize central story content or to sequence the important visual events. These results suggest that young children process songs shallowly. Moreover, it suggests that comprehensibility of content (Anderson et al., 1981) does not necessarily translate into increased comprehension, at least when children are learning a televised song. Children can sing songs that they do not understand, and it is not clear that they even think to look for any message. These findings, which parallel those reported in the nursery rhyme literature (Hayes et al., 1982), support a levels of processing model.

A refinement of the levels of processing approach, the transfer appropriate model of information processing (Morris et al., 1977), was used to examine whether young children direct their processing activities in ways that parallel the perceived task demands. That is, 
children may learn a song to sing it, resulting in good recitation skills, and learn a prose passage to comprehend its meaning. Those hypotheses were not supported here. Contrary to what a transfer appropriate model of information processing might predict, children did not appear to perceive songs as passages to be memorized verbatim, or prose presentations as those that should be understood. In Experiment 2, the prose condition was actually recited better than the song. Moreover, the meaning of the passage was not understood, even when it was presented in prose. Consequently, there was no support for a transfer appropriate model in Experiment 2.

However, the recitation and comprehension findings in Experiment 2 did not support the levels of processing model well either. In the levels of processing model, the song should be recited best and the prose passage understood best. Instead, the prose condition was recited best, and comprehension was poor across conditions. Recitation and comprehension scores were unrelated, which suggests that children may have processed different kinds of information independently.

Taken together, the results support a modified version of the levels of processing approach. More specifically, rather than conceptualizing information only as occurring at distinct levels, both experiments suggest that songs present children with stimuli that compete for their limited attention and processing resources. Children must then make decisions about how to allocate these scarce resources.

From a levels of processing approach (Craik \& Lockhart, 1972), both experiments suggest that songs, especially in a young child's native language, present young children with competing forms (or "levels") of stimuli. On one level, a child listens to the melodic structure of a song, and at the same time, listens to the words linked with that tune. The melodic structure could predispose children to listen to how the lyrics sound rather than to what they mean. In addition, an interference effect could occur when children simultaneously try to encode the exact lyrics of a song and process its meaning. Therefore, a modified levels of processing approach, in which the salience of different aspects of a song may compete for a child's processing capacity, may account for the results of the two studies.

Thus, in the first experiment, children learning the French version of "Frere Jacques" may have recited the lyrics because the words were unrecognizable and meaningless. Hearing the lyrics in English, by contrast, presented the English-speaking children with new, recognizable stimuli: words they had heard before. This additional level of information may have interfered with their ability to learn the English version of the song verbatim as their processing skills had to be shared with two competing activities: singing the song and understanding its meaning. In addition, either the melodic structure or the televised visual stimuli could have distracted children from comprehending the meaning. These kinds of distractors have previously been documented as a visual superiority hypothesis in which young children process televised visual stimuli at the expense of the auditory, semantic sound track (Hayes \& Birnbaum, 1980). Similar interference effects could occur for melody and prose (Morrongiello \& Roes, 1990), and they may explain why children could recite the French version of "Frere Jacques" better than the English version.

Multiple levels of stimuli were also presented to children in the second experiment, especially in the mixed conditions of song and prose. In these mixed song and prose conditions, the children not only had to process the sounds of the words and their meanings, but also had to interpret a change in the melodic structure of the activity. The change in 
structure may have interfered with the information processing activities that were already taking place. Put another way, children had to alter their processing "strategies" midstream, perhaps disrupting their ability to perform the task. This interpretation may explain, in part, why the children in the mixed conditions were significantly worse at reciting their phone number than were those in the prose-only condition.

The ability to recite one's phone number was also unrelated to children's comprehension of its meaning. These findings suggest that young children encode the verbal words and the nonverbal tune of a song in a nonintegrated (see Morrongiello \& Roes, 1990) rather than in an integrated fashion (see Serafine, Davidson, Crowder, \& Repp, 1986), perhaps because they are processed at different levels. The current findings are similar to those found for older children. For example, many fourth-grade children do not understand the meaning of the songs they hear (Greenfield et al., 1987), but comprehension does improve for junior high and high school students. Taken together, these studies suggest that songs are difficult to process through middle childhood, making songs a questionable educational technique for children. Even when children can sing a song, they do not appear to understand it.

One limitation of this research is that only two songs were examined. These songs may have been relatively difficult for children to understand, particularly since comprehension items sometimes tapped into implicitly, not just explicitly, presented content. In addition, one song was in French, and the other was a new tune about their phone number, a relatively abstract concept for a preschooler. Therefore, the comprehensibility of these songs may have been beyond children's range of comprehension, even in the English version of "Frere Jacques." For these songs, it would be difficult for children to substitute alternate words which had comparable meanings to the original lyrics because many of the original "words" were in a foreign language (Experiment 1) or were numbers (Experiment 2). Future research should:

1. Examine additional songs that have clear and comprehensible messages; and

2. Explore alternative rehearsal mechanisms for children to employ, such as enacting the lyrics of a song, as a way to improve children's comprehension.

In conclusion, contrary to popular opinion, the results reported here suggest that a song is a less useful mnemonic device for teaching young children information than is a prose presentation. A modified levels of processing model, in which competing levels of stimuli are considered in relation to memory performance, is supported by the data. That is, songs appear to present multiple levels of stimuli that can distract children from understanding the content.

At an applied level, the findings provide direction for educators and for creators of children's television programs. Because young children's comprehension benefits more from prose than from sung presentations, educators should tailor their presentations accordingly. Teaching children their "ABC's" with a song, for example, may only improve rote memory. Similarly, the tendency for educational television programs such as "Barney" and "Sesame Street" to sing songs as an aid for comprehension may well be overemphasized. This technique may actually distract young children from the learning task, rather than improving their performance. To maximize comprehension of content, teachers and educational television programs may need to talk more, and sing less. 
Acknowledgements: We would like to thank Arminda Gomes, Nanette Jarmain, and Christina D'Giacamo for their assistance in data collection; Siu-Lan Tan for writing an original song for one study; and Huey Jin Soon for organizing the choral presentation of "Frere Jacques." We also thank the students, teachers, and parents of the Washington International School, the Owl School, the Children's World Learning Center, and the Montessori School for their participation and assistance in these studies.

\section{REFERENCES}

Anderson, D.R., \& Lorch, E.P. (1983). Looking at television: Action or reaction. In J. Bryant \& D.R. Anderson (Eds.), Children's understanding of television: Research on attention and comprehension. New York: Academic.

Anderson, D.R., Lorch, E.P., Field, D.E., \& Sanders, J. (1981). The effects of TV program comprehensibility on children's visual attention and story comprehension. Child Development, 52, 151-157.

Calvert, S.L., \& Tart, M. (1993). Song versus verbal forms for very-long-term, long-term, and short-term verbatim recall. Journal of Applied Developmental Psychology, 14, 245-260.

Calvert, S.L. (in press). The form of thought. To appear in I. Sigel (Ed.), Theoretical perspectives in the concept of representation. Hillsdale, $\mathrm{NJ}$ : Erlbaum.

Collins, W.A. (1970). Learning of media content: A developmental study. Child Development, 41, 1133-1142.

Craik, F., \& Lockhart, R. (1972). Levels of processing: A framework for memory research. Journal of Verbal Learning and Verbal Behavior, 11, 521-533.

Greenfield, P.M., Bruzzone, L., Koyamatsu, K., Satuloff, W., Nixon, K., Brodie, M., \& Kingsdale, D. (1987). What is rock music doing to the minds of our youth? A first experimental look at the effects of rock music lyrics and music videos. Journal of Early Adolescence, 7, 315-329.

Greenfield, P.M. (1993). Representational competence in shared symbol systems: Electronic media from radio to television. In R.R. Cocking \& K.A. Renninger (Eds.), The development and meaning of psychological distance (pp. 161-183). Hillsdale, NJ: Erlbaum.

Hayes, D., \& Birnbaum, D. (1980). Preschoolers' retention of televised events: Is a picture worth a thousand words? Developmental Psychology, 16, 410-416.

Hayes, D., Chemelski, B., \& Palmer, M. (1982). Nursery rhymes and prose passages: Preschoolers' liking and short-terin retention of story events. Developmental Psychology, 18, 49-56.

Hyman, I.E., \& Rubin, D.C. (1990). Memorabeatlia: A naturalistic study of long-term memory. Memory \& Cognition, 18, 205-214.

Johnson, J.L., \& Hayes, D.S. (1987). Preschool children's retention of rhyming and nonrhyming text: Paraphrase and rote recitation measures. Journal of Applied Developmental Psychology, 8, 317-327.

Morris, C.D., Bransford, J.D., \& Franks, J.J. (1977). Levels of processing versus transfer appropriate processing. Journal of Verbal Learning and Verbal Behavior, 16, 519-533.

Morrongiello, B., \& Roes, C. (1990). Children's memory for new songs: Integration or independent storage of words and tunes? Journal of Experimental Child Psychology, 50, 25-38.

Rubin, D. (1977). Very long-term memory for prose and verse. Journal of Verbal Learning and Verbal Behavior, $16,611-621$.

Serafine, M.L., Davidson, J., Crowder, R.C., \& Repp, B.H. (1986). On the nature of melody-text integration in memory for songs. Journal of Memory and Language, 25, 123-135.

Sloboda, J. (1985). The musical mind: The cognitive psychology of music. Oxford: Oxford University Press.

Wright, J.C., Huston, A.C., Ross, R., Calvert, S.L., Rollandelli, D., Weeks, L.A., Raessi, P., \& Potts, R. (1984). Pace and continuity of television programs: Effects on children's attention and comprehension. Developmental Psychology, 20, 653-666. 